\title{
The Relationship between \%BML, Urine Color, Thirst Level and Urine Indices of Hydration Status
}

\author{
Yasuki Sekiguchi Courteney L. Benjamin Cody R. Butler Margaret \\ C. Morrissey Erica M. Filep Rebecca L. Stearns Douglas J. Casa \\ Department of Kinesiology, Status Korey Stringer Institute, University of Connecticut, Storrs, CT, USA
}

\begin{abstract}
Introduction: Dehydration is known to impair health, quality of daily life, and exercise performance [1]. While several methods are utilized to assess fluid balance, there is no gold standard to assess hydration status [2]. Cheuvront and Kenefick [3] suggested the use of a Venn diagram, which consists of $\%$ body mass weight (BML), urine color, and thirst level (WUT) to measure hydration status and fluid needs. However, no study to date has examined the relationship between the WUT criteria and hydration status measured by urine indices. Objective: The purpose of this study was to investigate the relationships between urine-specific gravity (USG), urine osmolality ( $\left.U_{\mathrm{OSM}}\right)$, and the WUT criteria. Methods: Twenty-two females (mean \pm SD; age, $20 \pm 1$ year; weight, $65.4 \pm 12.6 \mathrm{~kg}$ ) and twenty-one males (age, $21 \pm 1$ year; body mass, $78.7 \pm 14.6 \mathrm{~kg}$ ) participated in this study. First-morning body mass, urine color, USG, $U_{\mathrm{OSM}}$, and thirst level were collected for 10 consecutive days. First 3 days were utilized to establish a euhydrated baseline body weight. $\% \mathrm{BML}>1 \%$, urine color $>5$, and thirst level $\geq 5$ were used as the dehydration thresholds. The number of markers that in-
\end{abstract}

dicated dehydration levels was summed when each variable met each threshold. One-way ANOVA with Tukey pairwise comparison was used to assess the differences in USG and $U_{\text {OSM }}$, followed by a calculation of effect size (ES). Results: Figure 1 indicates the differences of $U_{\text {OSM }}$ based on the WUT criteria. For $U_{\mathrm{OSM}}$, "2 markers indicated" (mean [M] \pm SD [ES], $705 \pm 253$ mOsmol [0.43], $p=0.018$ ) was significantly higher than "1 marker indicated" ( $\mathrm{M} \pm \mathrm{SD}, 597 \pm 253 \mathrm{mOsmol})$. Additionally, "zero marker indicated" (509 \pm 249 mOsmol) was significantly lower than "3 markers indicated" (M \pm SD [ES], $761 \pm 250$ mOsmol, [1.01], $p=0.02$ ) and "2 markers indicated" ([ES], [0.78], $p=0.004)$. However, there was no statistical difference between "3 markers indicated" ([ES], [0.65], $p=0.13$ ) and "1 marker indicated." For USG, "3 markers indicated" (M $\pm \mathrm{SD}$ [ES], $1.021 \pm 0.007$ [0.57], $p=0.025)$ and "2 markers indicated" (M \pm SD [ES], $1.019 \pm 0.010$ [0.31], $p=0.026$ ) were significantly higher than "1 marker indicated" (M $\pm S D, 1.016$ $\pm 0.009)$. Additionally, "zero marker indicated" (1.014 \pm 0.005$)$ was significantly lower than "3 markers indicated" ([ES], [1.21], $p=0.005$ ) and "2 markers indicated" ([ES], [0.54], $p=$ 0.009). Conclusion: When 3 markers indicated dehydration karger@karger.com www.karger.com/anm

Karger $\stackrel{\text { ' }}{5}$

GOPEN ACCESS
(C) 2021 The Author(s)

Published by S. Karger AG, Basel

This article is licensed under the Creative Commons AttributionNonCommercial-NoDerivatives 4.0 International License (CC BYNC-ND) (http://www.karger.com/Services/OpenAccessLicense) Usage and distribution for commercial purposes as well as any distribution of modified material requires written permission.
Correspondence to:

Yasuki Sekiguchi, yasuki.sekiguchi@uconn.edu 


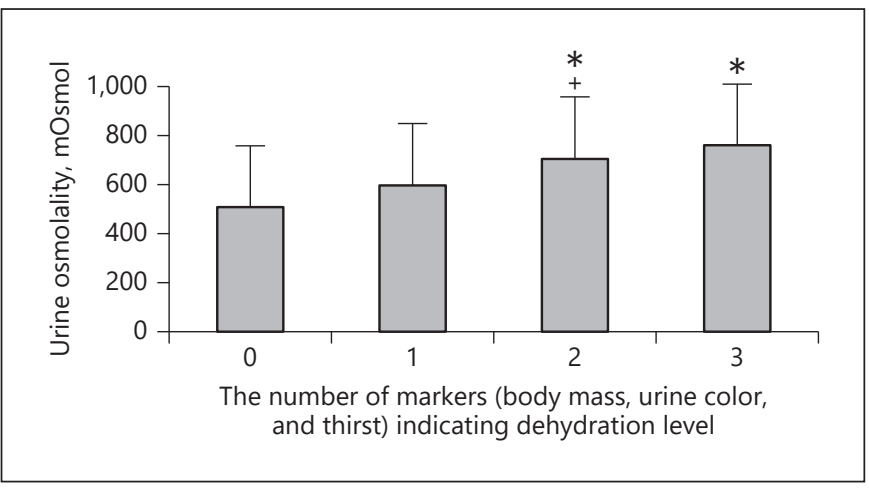

Fig. 1. The number of markers (body mass, urine color, and thirst) indicating dehydration in UOSM. $\left({ }^{*}\right)=$ different from 0 and $(+)=$ different from $1(p<0.05)$. UOSM, urine osmolality.

levels, U OSM and USG were greater than euhydrated cut points. When 2 markers indicated dehydration levels, USG was higher than the euhydrated cut point. Additionally, $U_{\text {OSM }}$ and USG were significantly lower when zero or 1 marker indicated dehydration levels. Thus, the WUT criteria are a useful tool to assess hydration status. Athletes, coaches, sports scientists, and medical professions can use this strategy in the field settings to optimize their performance and health without consuming money and time.

(C) 2021 The Author(s)

Published by S. Karger AG, Basel

\section{Statement of Ethics}

This research was conducted ethically in accordance with the World Medical Association Declaration of Helsinki. Following an explanation of the study procedures, which was approved by the Institutional Review Board at the University of Connecticut (H18-115), participants provided written and informed consent to participate.

\section{Conflict of Interest Statement}

Y.S. received travel expenses and registration fees from Danone Research to attend the 2019 Hydration for Health Scientific Conference. The writing of this article was supported by Danone Nutricia Research and the authors declare no other conflicts of interest. The authors declare that no financial or other conflict of interest exists in relation to the contents of the paper and did not receive financial support for the writing of this article. CamelBak founded this study. CamelBak is corporate partner of KSI, where Douglas Casa is CEO. CamelBak did not impact any process of this manuscript.

\section{Author Contributions}

Y.S. and C.B. led this study and contributed to all aspects of this study, including planning, data collection, analysis, and writing a manuscript. D.C. and R.S. were PI of this study. Other authors contributed to the data collection and writing the manuscript.

\section{References}

1 Adams JD, Scott DM, Brand NA, Suh H-G, Seal AD, McDermott BP, et al. Mild hypohydration impairs cycle ergometry performance in the heat: a blinded study. Scand J Med Sci Sports. 2019 May;29(5):686-95.
2 Kavouras SA. Assessing hydration status. Curr Opin Clin Nutr Metab Care. 2002 Sep; 5(5):519-24.

3 Cheuvront SN, Kenefick RW. Am I drinking enough? Yes, no, and maybe. J Am Coll Nutr. 2016;35(2):185-92. 